\title{
Editorial Article for the Journal of Microscopy Research
}

\author{
Marc Porti \\ Departament d'Enginyeria Electrònica, Universitat Autònoma de Barcelona, Barcelona, Spain. \\ Email: marc.porti@uab.es \\ Received May $12^{\text {th }}, 2013$; revised June $18^{\text {th }}, 2013$; accepted July $5^{\text {th }}, 2013$ \\ Copyright (C) 2013 Marc Porti. This is an open access article distributed under the Creative Commons Attribution License, which \\ permits unrestricted use, distribution, and reproduction in any medium, provided the original work is properly cited.
}

I have the honor to be a member of the Editorial Board of the Microscopy Research journal, of which I am convinced it has an enormous potential of growth. First, because it is a open access journal and, secondly, because it deals with a key field in the scientific and technological development of our society: microscopy.

Knowledge and scientific achievements dissemination of mankind are really important for the progress of our society. The more the knowledge is accessible, the greater is its dissemination, which is mainly carried out from the publication of the scientific advances in journals. To that end, open access journals have a very important task, since they provide access to information without limits and without charge.

Regarding microscopy (whose origin comes from micro-, small), it is very important to remind that the scientific progress has always been closely related to the development of measurement techniques of the external world. Among them, microscopy is highlighted, which has given the chance to see objects smaller and smaller. Traditional microscopy is based on the difraction, reflection or refraction of any kinds of radiation. One of the most common is the optical microscope, invented and developed during the 16 - 17th centuries, which allowed the observation for the first time of blood cells, bacteria, protozoans, etc. However, their resolution is limited to the range of $\mu \mathrm{m}$.

For high resolution measurements of surfaces, Scanning Electron Microscopy (SEM), which was developed around the thirties of the last century, has been thoroughly used. SEM and several improvements since its invention have allowed the investigation of morphological and compositional characteristics of surfaces at the nanoscale. However, during the last two decades of the 20th century, microscopy experienced a very important revolution thanks to the development of Scanning Probe
Microscopes (SPMs), which have been demonstrated to be very powerful tools for surface metrology. As an example, STM (Scanning Tunneling Microscope, developed in 1981) has enough resolution to distinguish atomic positions of the analyzed sample. An STM basically consists of an extremely ultrasharp tip that scans the target surface at very small distances and measures the tunneling current between tip and the sample to get information of the morphology. The development of the Atomic Force Microscope (AFM) in 1986 spread the applications of SPMs and allowed the investigation of any kinds of surfaces, including non-conductive samples. As the STM, the AFM uses a very sharp tip but, in this case, instead of measuring the tunneling current, the AFM detects the interaction forces that act over the tip to reproduce the sample morphology. Its capability of imaging conductive and non-conductive surfaces in different ambients (including liquids) with a resolution of $\sim \mathrm{nm}$ has led the AFM to become a very useful tool in so diverse fields as Materials Sciences, Health Sciences, Micro-Microelectronics, Biology and Chemistry. Moreover, within their short lifetimes, SPM techniques have already added many other capabilities to the initial surface analysis so that, although morphological information is still one of the main applications, nowadays it is also possible to measure other properties at the nanoscale as, for example, conductivity, mechanical properties, contact potential, among many others. The use and spread of all these microscopic techniques, which are nowadays very common in the current laboratories of universities and research centers, have revolutionized nanoscience and nanotechnology and have allowed an unprecedented scientific and technological development, which I am sure will keep in the future. I hope that the journal Microscopy Research gathers the publication of outstanding scientific papers related to this very hot-topic. 